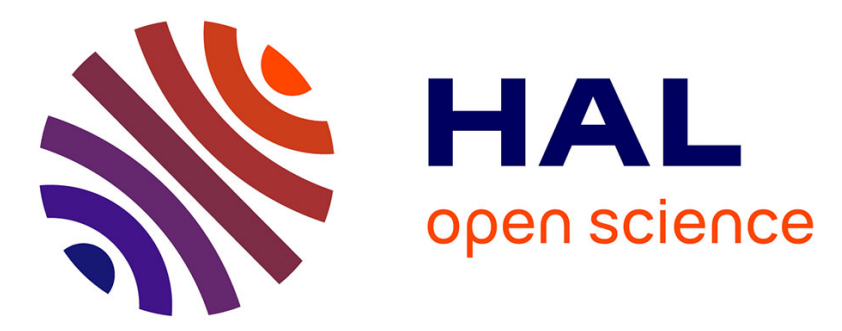

\title{
Effects of the air-steam mixture on the permeability of damaged concrete
}

Sonagnon Medjigbodo, Aveline Darquennes, Corentin Aubernon, Abdelhafid Khelidj, Ahmed Loukili

\section{To cite this version:}

Sonagnon Medjigbodo, Aveline Darquennes, Corentin Aubernon, Abdelhafid Khelidj, Ahmed Loukili. Effects of the air-steam mixture on the permeability of damaged concrete. Cement and Concrete Research, 2013, 54, pp.98-105. 10.1016/j.cemconres.2013.08.013 . hal-03286033

\section{HAL Id: hal-03286033 https://hal.science/hal-03286033}

Submitted on 18 Aug 2021

HAL is a multi-disciplinary open access archive for the deposit and dissemination of scientific research documents, whether they are published or not. The documents may come from teaching and research institutions in France or abroad, or from public or private research centers.
L'archive ouverte pluridisciplinaire HAL, est destinée au dépôt et à la diffusion de documents scientifiques de niveau recherche, publiés ou non, émanant des établissements d'enseignement et de recherche français ou étrangers, des laboratoires publics ou privés. 


\title{
Effects of the air-steam mixture on the permeability of damaged concrete
}

\author{
Sonagnon Medjigbodo a , Aveline Darquennes ${ }^{\mathrm{b}}$, Corentin Aubernon ${ }^{\mathrm{a}}$, Abdelhafid Khelidj ${ }^{\mathrm{c}}$, Ahmed Loukili ${ }^{\mathrm{a}, *}$ \\ a LUNAM Université, Institut de Recherche en Génie Civil et Mécanique (GeM UMR CNRS 6183), Centrale Nantes, 1 rue de la Noe, BP 92101 , F-44321 CEDEX 3 Nantes, France \\ ${ }^{\mathrm{b}}$ LMT/ENS Cachan/CNRS UMR 8535/UPMC/PRES Université Sud Paris, Cachan, France \\ c LUNAM Université, Institut de Recherche en Génie Civil et Mécanique (GeM UMR CNRS 6183), IUT de Saint Nazaire, 58 rue Michel Ange, BP 420 Heinlex, F-44600 Saint-Nazaire, France
}

Massive concrete structures such as the containments of nuclear power plant must maintain their tightness at any circumstances to prevent the escape of radioactive fission products into the environment. In the event of an accident like a Loss of Coolant Accident (LOCA), the concrete wall is submitted to both hydric and mechanical loadings. A new experimental device reproducing these extreme conditions (water vapor transfer, $140{ }^{\circ} \mathrm{C}$ and 5 bars) is developed in the GeM Laboratory to determine the effect of the saturation degree, the mechanical loading and the flowing fluid type on the concrete transfer properties. The experimental tests show that the previous parameters significantly affect the concrete permeability and the gas leakage rate. Their evolution as a function of the mechanical loading is characterized by two phases that are directly related to concrete microstructure and crack development.

\section{Introduction}

Knowing the concrete transfer properties is essential for the performance and durability of structures. Several concrete structures are designed to contain liquids (water or liquefied gas tanks) or gas (containment walls of nuclear power plants) and thus they have to resist to any liquid, gas and/or ion penetration to prevent contamination and corrosion $[1,2]$. Recent studies and field surveys $[1,3,4]$ show that the poor performance of some concrete structures is more or less directly related to the ability of these agents to penetrate into the material [5]. Permeability is one of the main durability indicators. According to Darcy's law, permeability is defined as an intrinsic material property. For example, its value does not depend on the injected fluid. This last point is true for sandstone or granite materials [6,7], but not for cement matrix materials. Indeed, water permeability is often lower (from 1 to 2 orders of magnitude) than gas permeability [8]. Almost all researchers agree that water interacts with the cement matrix, either by dissolving hydrates (mainly portlandite) or, by leading to an in-depth hydration of anhydrous cement particles [9]. It is also important to notice that gas permeability depends on several parameters: the mean free path covered by gas molecules, the pressure, the temperature and the nature of the gas $(\mathrm{N} 2, \mathrm{O} 2 \ldots)$ [10]. Moreover, massive concrete structures are rarely completely dry or completely saturated (test conditions for the measurements of gas or water permeability respectively). They are more often characterized by an intermediate state where water, water vapor and air coexist in the pore network. Quantification of concrete permeability under these

\footnotetext{
* Corresponding author.

E-mail address: ahmed.loukili@ec-nantes.fr (A. Loukili).
}

conditions is therefore a fundamental question. This is the reason why in this article a new experimental device is proposed.

Hereafter, we focus mainly on the specific case of leakage quantification through containment buildings of nuclear power plants for the case of a Loss of Coolant Accident (LOCA). Pressurized water reactors (PWRs) with a double reinforced concrete wall (Fig. 1) are constructed in France to improve their structural performance. The outer wall is designed to resist an external impact while the inner wall is mainly designed to limit leakage. The inner wall is characterized by bi-axial pre-stressing and has a $90 \mathrm{~cm}$ thickness. The space between the two containment walls is kept under slight depressurization ( $>15$ mbar) to filter any potential leaks from the inner containment $[11,12]$.

If a LOCA occurs, the ambient conditions are rapidly changing inside the inner containment building. The temperature increases up to $150{ }^{\circ} \mathrm{C}$ and the absolute pressure of a gas (a mixture of air and steam) reaches up to $0.52 \mathrm{MPa}$ (steam and air pressure equal to $0.372 \mathrm{MPa}$ and $0.148 \mathrm{MPa}$ respectively). Important gradients of temperature, pressure and relative humidity appear in the wall (as the inner face is subjected to a thermo-hydric loading and the outer face is kept at ambient conditions) leading to wall damage which increases the global permeability and thus the leakage rate of percolating gas through the concrete wall. In order to quantify leakage, in-situ experiments are conducted every ten years following the French recommendations that limit the leakage rate per day to $1.5 \%$ of total mass in the containment building [12,13]. In these tests, the inner containment building undergoes pressurization (dry air pressure up to 5.8 bars) at ambient temperature.

However, this approach does not consider explicitly all the parameters affecting the material behavior (for example the effect of fluid type flowing through the wall). Research has been done on the effect of mechanical and thermal loadings on the evolution of permeability using 


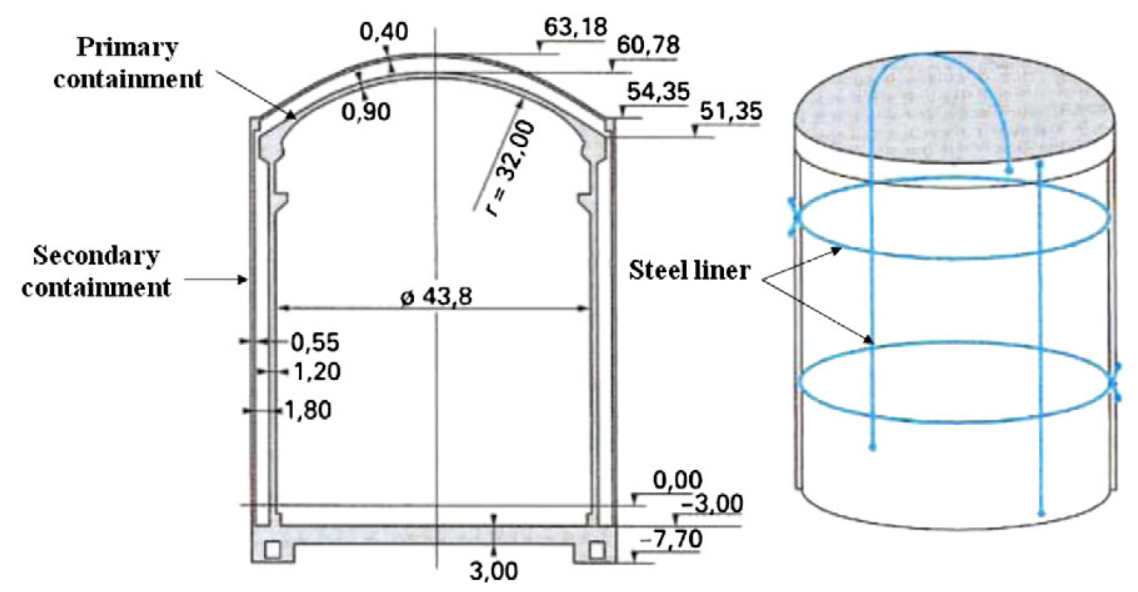

Fig. 1. Simplified drawing of a pressurized water reactor (PWR) [12].

injected air [14-17]. An exponential relationship linking permeability and damage was proposed by Picandet et al. [14]. In these experiments, permeability was measured on previously damaged specimens (after loading removal) and it was found that for low levels of compressive loading (inferior to $80 \%$ of ultimate strength), the residual permeability (ratio between measured and initial permeability) stays constant. Beyond $80 \%$, it increases significantly. Permeability measurements under maintaining loading are proposed by Choinska et al. [15] and Sugiyama et al. [16]. The two stages were confirmed (beyond and after $80 \%$ of ultimate strength), but during the first stage residual permeability slightly decreases.

The two stages were also observed for the evolution of water permeability as a function of the compressive loading $[18,19]$. In this case however, the threshold is located at $30-40 \%$ of the ultimate strength. It was also found that the temperature loading affects the gas permeability $[15,20]$. A significant increase in permeability is observed for large temperatures $\left(105{ }^{\circ} \mathrm{C}-200{ }^{\circ} \mathrm{C}\right)$ due to the development of micro-cracks and their gradual interconnection (related to the pore widening). Further studies [15] showed that the effect of temperature and loading on permeability could be decoupled. All the previous experimental campaigns were conducted on dry concrete specimens. In order to take into account the effect of water content, gas permeability tests were carried out on partially saturated concrete specimens [21] where it was found that permeability decreases with increasing degree of saturation.

The material behavior under LOCA conditions (air and steam percolation, pressure of 5.2 bars and temperature of $150{ }^{\circ} \mathrm{C}$ ) was studied by Billard [13] and Laghcha [22]. A non-cracked concrete wall was tested to determine the effect of a percolating fluid on permeability and its interaction with the cementitious matrix. Their work showed that the flow detected after the wall was principally dry air as steam condenses into concrete $[13,22]$. The transfer through a porous material submitted to temperature gradients induces several physical phenomena such as capillary water evapo-condensation, and capillary suction $[23,24]$. The gradual damage of the material under LOCA conditions increases significantly the complexity of these phenomena and therefore new tests are necessary in order to understand the physical mechanisms and to improve the performance of the numerical models.

A new experimental device allowing the production and injection of gas mixture (steam + nitrogen) on concrete specimens subjected to thermo-mechanical loadings has been developed in GeM (Institut de Recherche en Génie Civil et Mécanique). With this new device a more accurate reproduction of the LOCA conditions is possible. We present hereafter the first experimental campaign results. The purpose of this campaign is to determine the effects of temperature, degree of saturation, damage of wall and the influence of different types of percolating fluids on the permeability and leakage rate.

\section{Experimental program}

\subsection{Materials}

The studied concrete mixture, named B11, is a typical concrete composition used for the construction of nuclear parks. It consists of cement CEM II/A-LL 42.5R, limestone aggregates and river sand. Glenium 21 is added as superplasticizer. The mixture proportions are given in Table 1 . The slump, the compressive strength at 28 days $\left(f_{c 28}\right)$ and the water porosity measured according to the AFREM recommendations [25] are provided in Table 2.

Hollow cylindrical specimens (Fig. 2b) are cast following the NF P 18-404 standards [26]. The cylindrical borehole is created by placing a metallic bar (diameter equal to $14 \mathrm{~mm}$ ) in the center of the molds (Fig. 2a). This bar has to be rotated every hour to avoid its adhesion with concrete specimen.

After 1 day, all the specimens are demoulded and kept at $20{ }^{\circ} \mathrm{C}$ under water curing during 28 days. After, two types of test are realized:

(i) Test on dry specimens: To obtain these conditions, specimens are kept in an oven at $80{ }^{\circ} \mathrm{C}$ during eight months until a constant mass (mass change not exceeding $0.05 \%$ after $24 \mathrm{~h}$ ) is achieved.

(ii) Test on partially saturated specimens: To obtain different degrees of saturation, the specimen preparation is composed of several stages:

a. All specimens are kept during five months under water to obtain a saturation degree equal to $100 \%$. Their mass $M_{w}$ (g) is measured after this curing.

b. Then, specimens are drying in an air oven at $80{ }^{\circ} \mathrm{C}$ during several months until a constant mass $M_{d}(\mathrm{~g})$ is achieved. The intrinsic permeability is determined for each specimen.

c. The specimens are progressively re-saturated in order to obtain the required saturation degree. This value is determined with the Eq. (1) and the mass $M_{S R}(\mathrm{~g})$ is measured continuously during the moist curing. To obtain a low degree of saturation

Table 1

Concrete constituents and mix proportions.

\begin{tabular}{ll}
\hline Ingredient & Quantity $\left(\mathrm{kg} / \mathrm{m}^{3}\right)$ \\
\hline River sand, 0-5 mm & 772 \\
Gravel, 5-12.5 mm & 316 \\
Gravel, $12.5-25 \mathrm{~mm}$ & 784 \\
Cement & 350 \\
Effective water & 201 \\
Plasticizer & 1.23 \\
Water/cement ratio & 0.57 \\
\hline
\end{tabular}


Table 2

Concrete properties.

\begin{tabular}{lll}
\hline Slump $(\mathrm{mm})$ & $\mathrm{f}_{\mathrm{c} 28}(\mathrm{MPa})$ & Open water porosity (\%) \\
\hline 140 & 38.55 & 15
\end{tabular}

(about 50\%), specimens are firstly kept at $20{ }^{\circ} \mathrm{C}$ and $50 \%$ R.H. and secondly at $20{ }^{\circ} \mathrm{C}$ and $100 \%$ R.H. from one to two weeks. For significant degrees of saturation (from 50 to $90 \%$ ), a water curing at $20^{\circ} \mathrm{C}$ is applied during several days. In order to have a uniform saturation state, the extremities of specimens are covered with aluminum paper and they are kept in a watertight bag [27] until experimental campaign.

d. Dry air permeability test is performed. Before the permeability test, $M_{S R}$ is again measured to correct the degree of saturation.

$M_{S R}=\frac{S r *\left(M_{w}-M_{d}\right)}{100}+M_{d}$

\subsection{Experimental set-up}

The experimental set-up consists of a climatic chamber, a hydraulic loading frame MTS $500 \mathrm{KN}$ and a system of gas and liquid flow regulation to measure permeability (Fig. 3). The schematic illustration of the apparatus is shown in Fig. 4.

In this experiment, the imposed conditions are temperature $T$, total pressure $P_{t}$, relative humidity R.H. of the gas mixture to be injected inside the concrete specimen and the nitrogen flow rate $Q_{a s}(\ln / \mathrm{min})$. From these experimental parameters, the required water flow rate $Q_{w}(\mathrm{~g} / \mathrm{h})$ is calculated using Eq. (2). This relation is based on two assumptions: an ideal gas and a stationary state established during the flow.

$Q_{w}=60 * Q_{a s} * \frac{M_{w}}{M_{a s}} * \frac{P_{v p}}{P_{a s}} * \rho_{a s}$

where $P_{v p}=R . H . * P_{v s a t}(T)$ and $P_{a s}=P_{t}-P_{v p}$ are the partial pressures of water vapor and nitrogen (Pa) respectively, $P_{v s a t}(\mathrm{~Pa})$ the saturated vapor pressure of water at temperature $T, M_{w}(\mathrm{~g} / \mathrm{mol})$ and $M_{a s}(\mathrm{~g} / \mathrm{mol})$ are the water vapor and nitrogen molar mass and $\rho_{a s}(\mathrm{~g} / \mathrm{l})$ is the nitrogen density.

Before the beginning of the test, all the parts of the device placed inside the climatic chamber (Fig. 4) are heated to the test temperature in order to avoid any water vapor condensation in the experimental device. In the mix box, distilled water and nitrogen are introduced. The flow rate of both fluids (water and nitrogen) is regulated thanks to a liquid and gas mass flow controller (Fig. 4). Liquid is transformed into steam by means of an evaporation device which is subjected to the same temperature as that of the gas mixture. The total pressure of the injected mix is regulated thanks to a pressure regulator equipped with an evacuation gate placed directly after the evaporation device. The temperature and the relative humidity of the injected mix are continuously measured by the transducer. The mix flows to the specimen through a heated pipe. A metallic drilled plate is placed on the top of the specimen allowing the mixture gas injection into the cylindrical borehole. In order to ensure a radial flow of the gas, the upper and lower faces of the cylindrical specimen are protected by an aluminum film, circular rubber tight joints and silicone grease (Fig. 4); a minimum load of $5 \mathrm{kN}$ is also applied on the concrete specimen placed between the two platens of the hydraulic. To avoid leakage, a flexible tube is placed around the specimen. At the downstream of the specimen, the temperature and the relative humidity of the output gas mixture are also continuously measured. Then, the mix is evacuated using an isolated pipe fitted by a condenser. At the end of the system, the dry gas flow is measured by means of a gas flow meter. The accuracy of the sensor measurements is $\pm 0.2{ }^{\circ} \mathrm{C}$ for the temperature and $\pm 2 \%$ for relative humidity.

When the relative humidity of the output gas mixture is known, the absolute humidity may be calculated as follows:

$a_{s}=\frac{H_{R S} * P_{v s a t}(T) * M_{w}}{R T}$

where $a_{s}\left(\mathrm{~g} / \mathrm{m}^{3}\right), M_{w}(\mathrm{~g} / \mathrm{mol}), T(\mathrm{~K}), R\left(\mathrm{~J} \cdot \mathrm{mol}^{-1} \cdot \mathrm{K}^{-1}\right), P_{v s a t}(\mathrm{~Pa})$ and $H_{R S}$ $(-)$ are the output absolute humidity, the molar mass of water vapor, the mix temperature, the ideal gas constant, the saturated vapor pressure of water at temperature $T$ and the output relative humidity respectively.

At mix flow stabilization (from 24 to $60 \mathrm{~h}$ in our study), a compressive loading is applied on the specimen with a displacement rate of $0.02 \mathrm{~mm} / \mathrm{min}$ up to the required load level. Then the dry gas leakage rate and the output relative humidity of the gas mixture are measured again in order to obtain the effect of the mechanical loading.

To validate partially our device, two test campaigns (one with our experimental set-up and one with the device developed by Choinska et al. [15]) were realized to measure the dry gas permeability on the same concrete specimen and with the same experimental conditions $\left(20{ }^{\circ} \mathrm{C}-50 \%\right.$ R.H.). Results are shown in Fig. 5. The agreement between both apparatus is quite good.

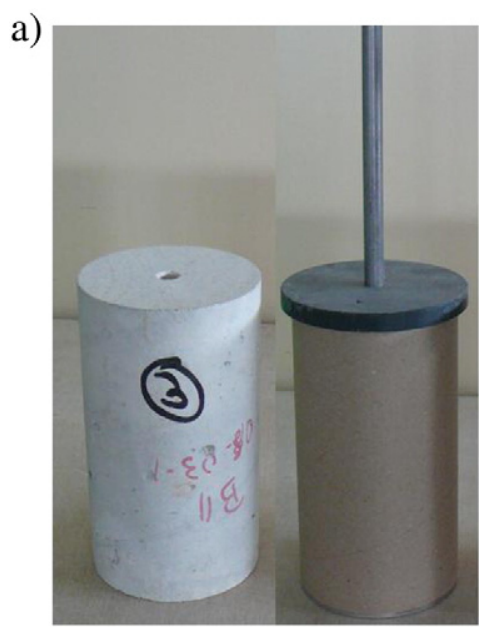

b)
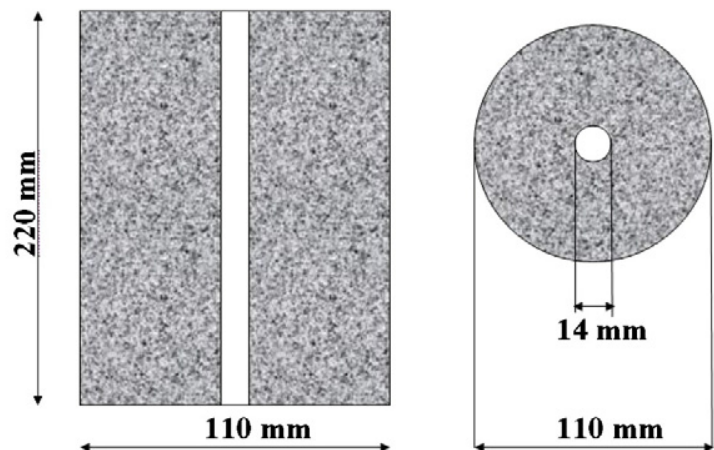

Fig. 2. (a) Concrete specimen and its mold - (b) Specimen geometry. 


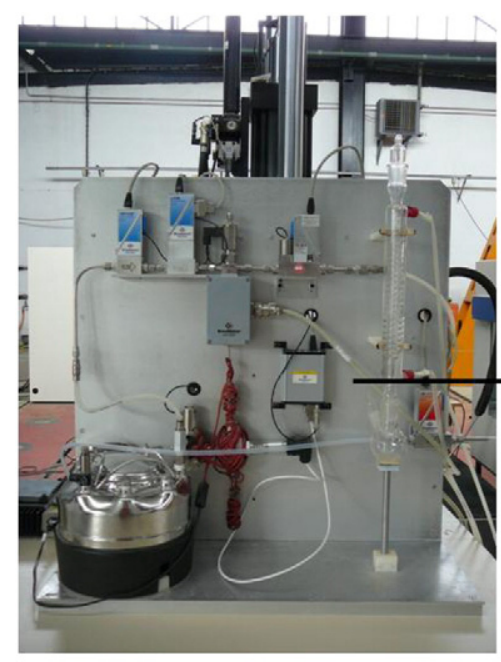

(1)

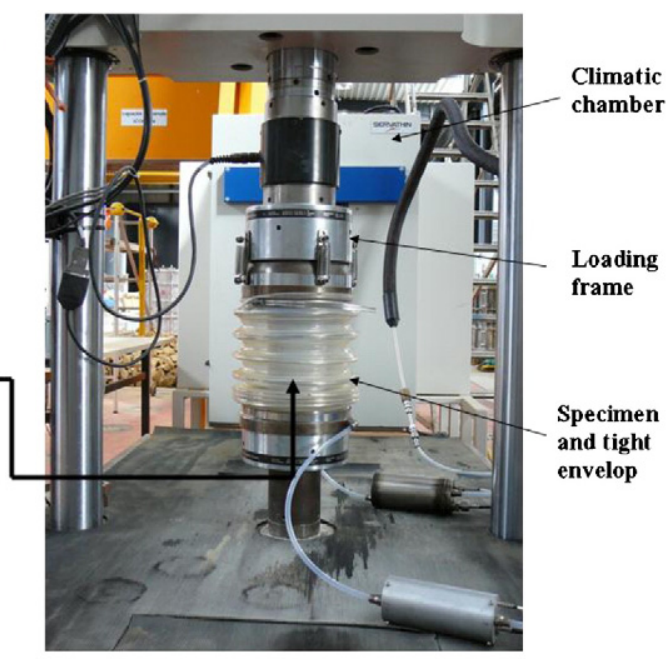

(2)

Fig. 3. System of gas and liquid regulation (1), Hydraulic loading frame with the specimen (2).

\section{Results and discussion}

\subsection{Influence of hydro-mechanical loading on concrete permeability}

In this section, the influence of water content located in the porous network and the loading level on gas permeability are studied. Permeability measurements were realized on partially saturated concrete specimens (saturation degrees: $0 \%, 25 \%, 44 \%$ and $81 \%$ ) at different gas (nitrogen), pressure levels $(0.1 ; 0.2 ; 0.3$ and $0.4 \mathrm{MPa})$. For each saturation degree, one concrete specimen was tested. The tests were performed at ambient temperature. At each pressure level, the nitrogen leakage rate $Q_{t}\left(\mathrm{~m}^{3} / \mathrm{s}\right)$ was measured and the apparent (or effective) permeability $k_{a}\left(m^{2}\right)$ was calculated using the Darcy's law adapted for cylindrical hollow specimens supposing a unidirectional laminar flow (Eq. (4)).

$k_{a}=\frac{P_{i} * Q_{i} * \mu *\left(\mathrm{r}_{2}-\mathrm{r}_{1}\right)}{\pi * H *\left(P_{i}^{2}-P_{a t m}^{2}\right) * \mathrm{r}_{1}}$

where $P_{i}$ and $P_{a t m}(\mathrm{~Pa})$ are the injection and atmospheric pressure respectively, $\mu(\mathrm{Pa} \cdot \mathrm{s})$ is the fluid dynamic viscosity, $H(\mathrm{~m})$ is the height and $r_{1}$ and $r_{2}$ are the inner and outer radius of the specimen.
Based on the Klinkenberg approach [24], the concrete intrinsic permeability $k_{v}\left(m^{2}\right)$, valid for dry concrete specimens, is calculated using Eq. (5) (valid for a laminar gas flow).

$k_{a}=k_{v}\left(1+\frac{\beta}{P_{m}}\right)$

where $P_{m}=\frac{P_{i}+P_{a t m}}{2}(\mathrm{~Pa})$ is the average gas pressure and $\beta(\mathrm{Pa})$ is the Klinkenberg coefficient. The parameter $\beta$ gives an indication about the pore size available for the gas flow in cement matrix and it depends on material and percolating gas.

For each specimen at a given saturation degree $S r$, the relative gas permeability $k_{\mathrm{rg}}$ is calculated from:

$k_{r g}(S R)=\frac{k_{a}(S r)}{k_{v}}$.

According to its definition, $k_{\mathrm{rg}}$ varies in the range of $[0 ; 1]$ whatever the specimen considered. Results about permeability measurements prior to mechanical loading are presented in Fig. 6 and Table 3. Fig. 6 displays effective permeability $k_{a}$ for different degrees of saturation and gas pressures. The results confirm the good linearity between $k_{a}$ and $1 / P_{m}$. In accordance with results obtain by Abbas et al. [21], Picandet et al. [14], and Vilain et al. [28], the results given in Table 3 show that the

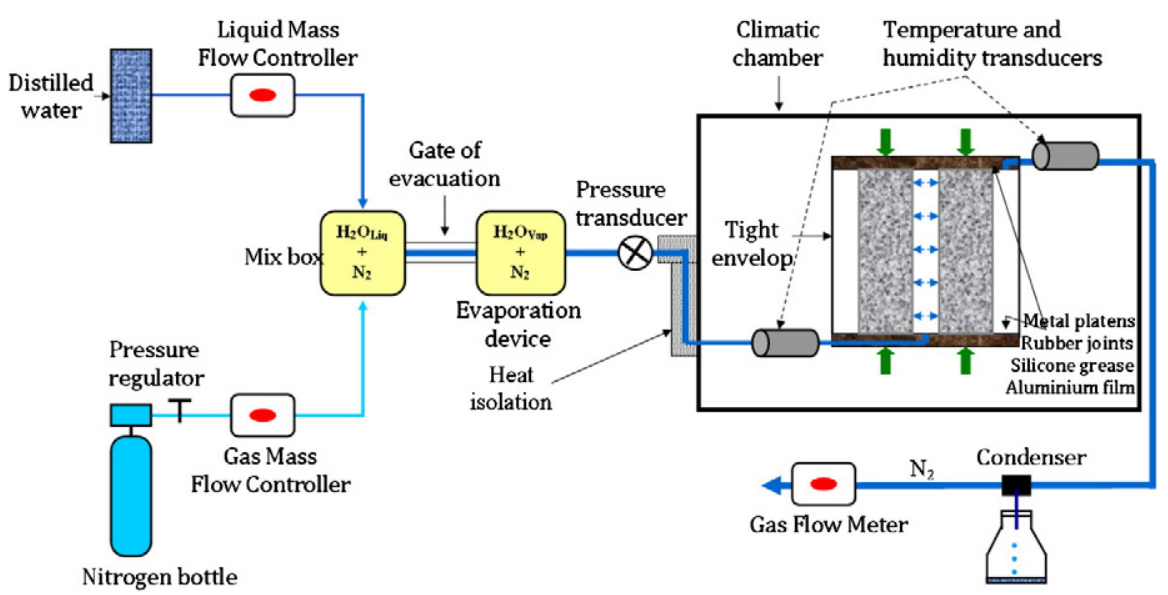

Fig. 4. Schematic illustration of test equipment. 


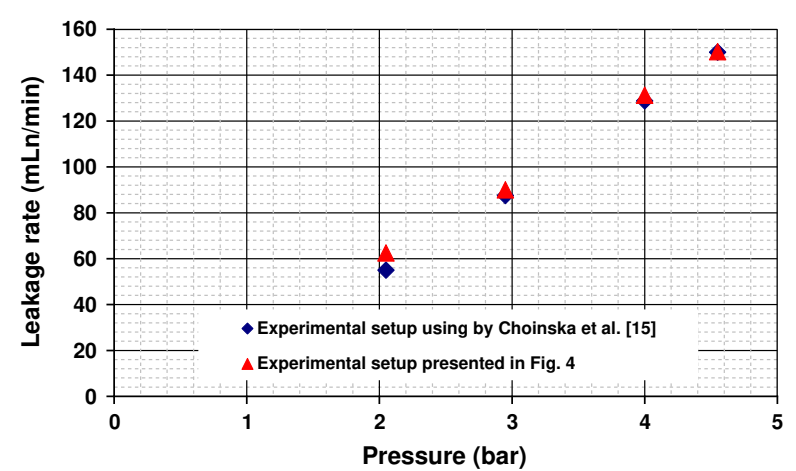

Fig. 5. Comparison of the nitrogen leakage rate measured with the device developed in this study and those obtained with the experimental setup from Choinska et al. [15].

relative permeability decreases with the degree of water saturation $(S r)$. According to Kelvin's law, water tends to occupy pores characterized by small diameter due to capillary effect. This phenomenon induced pore clogging. The continuity of the liquid phase is also possible through pore network even if $R . H$. is inferior to $100 \%$. Therefore, a part of the pore volume becomes inaccessible to gas leading to a decrease in gas permeability. According to Abbas et al. [21], the presence of a liquid phase reduces the non-viscous flow rate as soon as the saturation degree increases. As the Klinkenberg coefficient takes into account in the contribution of the non-viscous flow, it decreases too.

The specimens were then loaded at different percentages (from 35 to 95\%) of the ultimate compressive strength. At each loading level, the gas permeability was measured. Results are shown in Fig. 7 and the permeability evolution can be divided in two phases for all the studied saturation degrees. During the first phase, the permeability decreases and then it increases till its initial value. The second phase is characterized by an important permeability increase. These observations are similar to results obtained for dry concrete specimens [15]. The transition between phases 1 and 2 occurs at a stress level about $76 \%$ of the ultimate compressive strength. A more detailed description of these two phases is given below:

Phase 1: The permeability ratio is inferior to one for all saturation degrees. In this phase, the permeability ratio tends to decrease slightly and then increase up to one (Fig. 7).

The first stage is attributed to the contraction of the solid skeleton under loading. It leads to the partial closure of pores, water redistribution into the pores and micro-cracks $[15,29]$. There is a competitive effect between these phenomena. As the value of permeability ratio (Fig. 7) is inferior to one, the two first phenomena seem to be more important. This effect is clearly marked for the permeability

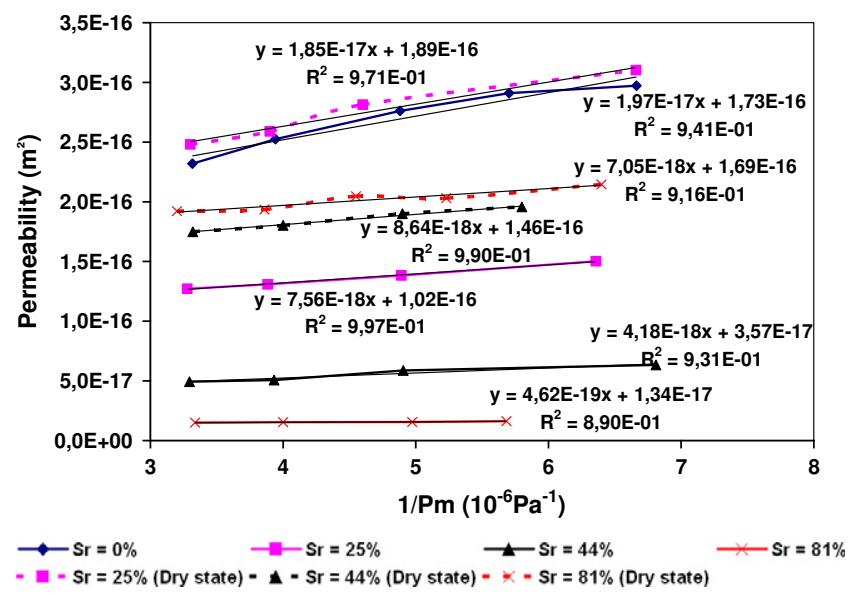

Fig. 6. Apparent permeability for different degrees of saturation and gas pressures.
Table 3

Relative gas permeability and Klinkenberg coefficient for concrete specimens characterized by different degrees of saturation.

\begin{tabular}{lll}
\hline $\operatorname{Sr}(\%)$ & $\mathrm{k}_{\mathrm{rl}}(-)$ & $\beta(\mathrm{MPa})$ \\
\hline 0 & 1.00 & 0.114 \\
25 & 0.54 & 0.074 \\
44 & 0.22 & 0.117 \\
81 & 0.08 & 0.034 \\
\hline
\end{tabular}

ratio at the highest degree of saturation (81\%). In Table 4, it appears that the Klinkenberg coefficient for saturation levels equal to $0 \%$ and $81 \%$ increases significantly during loading. As this parameter is inversely proportional to the radius of the capillaries pores [10], it can be assumed that mechanical loading generates a decrease in pore radius, thus in the global porosity. Notice that at lower degrees of saturation (25\%), the Klinkenberg coefficient evolution is not clear. Since the experimental campaign is essentially macroscopic, and little information are provided in the literature, it is very difficult to determine the predominant factors influencing this coefficient. Thus, these results have to be confirmed by supplementary tests.

The second stage is characterized by the development of diffused micro-cracks through all the cement pastes [15]. Consequently, the permeability increases until it reaches its initial value (Fig. 7).

Phase 2: During this phase, the specimen is progressively damaged. Micro-cracks coalesce, grow and are progressively interconnected to form macro-cracks. This network of cracks leads to a permeability increase. Some studies show that moisture content causes degradation in the compressive strength of concrete [30,31]. However, Picandet et al. [14] show that the increase of permeability is independent of the specimen moisture content. According to these authors, only the crack pattern controls the global gas flow on damaged specimens.

\subsection{Measurement of the mix gas leakage rate}

\subsubsection{Stabilization state of an air and steam mix flow}

Before the test, all the specimens were completely dry. Thus, their initial saturation degree is supposedly equal to zero. To approach the LOCA conditions, permeability tests were realized with a percolating fluid composed with air (nitrogen) and steam. For this kind of tests, it is important to obtain a steady state flow. The definition of a steady state is clear for the case of a water or dry gas flow. For a steam flow however, the situation is highly more complex. Several coupled physical phenomena (adsorption, isothermal and capillary condensation) happen during the steam transfer [32,33] leading to a partial saturation of dry porous materials. Thus, the space available for gas transport is modified and its intensity is reduced due to the condense water in the pore network. In addition, the water vapor transport seems to be essentially a diffusive phenomenon. Theoretical investigations of

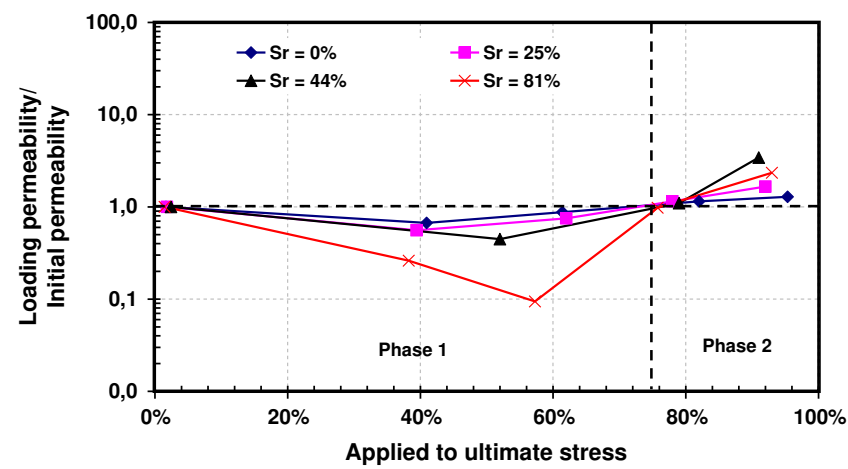

Fig. 7. Evolution of the gas permeability for partially saturated concrete specimens under an increasing loading. 
Table 4

Evolution of Klinkenberg coefficient for partially saturated concrete specimens under an increasing loading.

\begin{tabular}{llllllll}
\hline$\beta(\mathrm{MPa})$ & $\mathrm{F} / \mathrm{F}_{\mathrm{R}}(\%)$ & \multicolumn{7}{l}{} \\
\cline { 2 - 7 } & 2 & 40 & 50 & 60 & 76 & 80 & 90 \\
\hline $\mathrm{Sr}=0 \%$ & 0.114 & 0.145 & - & 0.183 & - & 0.094 & 0.092 \\
$\mathrm{Sr}=25 \%$ & 0.074 & 0.016 & - & 0.014 & - & 0.089 & 0.023 \\
$\mathrm{Sr}=44 \%$ & 0.117 & - & 0.151 & - & - & 0.051 & 0.134 \\
$\mathrm{Sr}=81 \%$ & 0.034 & 0.175 & - & 0.933 & 5.370 & & 0.228 \\
\hline
\end{tabular}

the water vapor flow in concrete were beyond the scope of this work. Following previous studies [24,34-36], it also appears clearly that a steady state of the mixture cannot be reached. However, a stabilization state of the two fluid transfers can be expected. In this study, this condition is characterized by a constant value of output absolute humidity and nitrogen flow rate. Notice that a significant time is needed to reach this stabilization state $[34,37]$.

To illustrate this explanation, a test is realized with a mix of nitrogen and steam injected at $120^{\circ} \mathrm{C}$ as described in Section 2.2. Moreover, to obtain a uniform temperature in the specimen, the required temperature $\left(120^{\circ} \mathrm{C}\right)$ is applied during $60 \mathrm{~h}$ before the injection of air and steam. Experimental conditions are given in Table 5 and the evolution of the output parameters (nitrogen flow rate $Q_{a}$ and absolute humidity $a_{s}$ ) is shown in Fig. 8. We describe hereafter how a stabilization state (the output absolute humidity and nitrogen flow rate became constant) is obtained for the studied air and steam mix.

During the first hours following the injection, the output absolute humidity stays low whereas the output nitrogen flow rate decreases rapidly. This last observation is due to a decrease in the paths accessible to nitrogen flow because of the formation of plugs in the porous network by steam condensation. In porous media as concrete, small pores are filled first. Once the menisci in the smallest pores become flatten, water fills the largest pores [34]. The maximum size of pores filled by water is determined from the Kelvin-Laplace relation (Eq. (7)). It is equal to about $3 \mu \mathrm{m}$ (experiment conditions: $80 \%$ R.H. and $120{ }^{\circ} \mathrm{C}$ ). From this result and the cumulative pore-size curve measured by mercury porosity [15], it appears that $70 \%$ of the pore network can be saturated. Nevertheless, the Kelvin-Laplace relation is based on the assumption that the pores are cylindrical and the water is a perfectly wetting liquid [38].

$r=-\frac{2 \sigma_{l / g} * M_{l}}{R T \rho_{l} * \ln (h r)}$

where $\sigma_{l / g}(\mathrm{~N} / \mathrm{m})$ is the liquid surface tension $\left(54.96 * 10^{-3} \mathrm{~N} / \mathrm{m}\right.$ at $\left.120{ }^{\circ} \mathrm{C}[39]\right), M_{l}$ the water molar mass ( $\left.\mathrm{g} / \mathrm{mol}\right), T$ the absolute temperature, $R$ the universal gas constant, $\rho_{l}\left(\mathrm{~kg} / \mathrm{m}^{3}\right)$ the water density and $h r$ the relative humidity.

Then the nitrogen leakage rate becomes constant and the value of the output absolute humidity begins to significantly increase until stabilization (after $60 \mathrm{~h}$ ). When the equilibrium is reached in the capillary pore, the different phases move independently through the porous network [34]. Stabilization happens thus later in this case than that for a gas test (after $1 \mathrm{~h}$ ). A similar observation is made by Laghcha [22]. Furthermore, more tests were realized with this experimental device but for different relative humidity and a constant total pressure of the

Table 5

Parameters imposed at specimen input and output.

\begin{tabular}{llll}
\hline Input & & Output \\
\hline Temperature $\left({ }^{\circ} \mathrm{C}\right)$ & Absolute pressure (bars) & Relative humidity (\%) & Pressure (bar) \\
120 & 3.4 & 80 & 1 \\
\hline
\end{tabular}

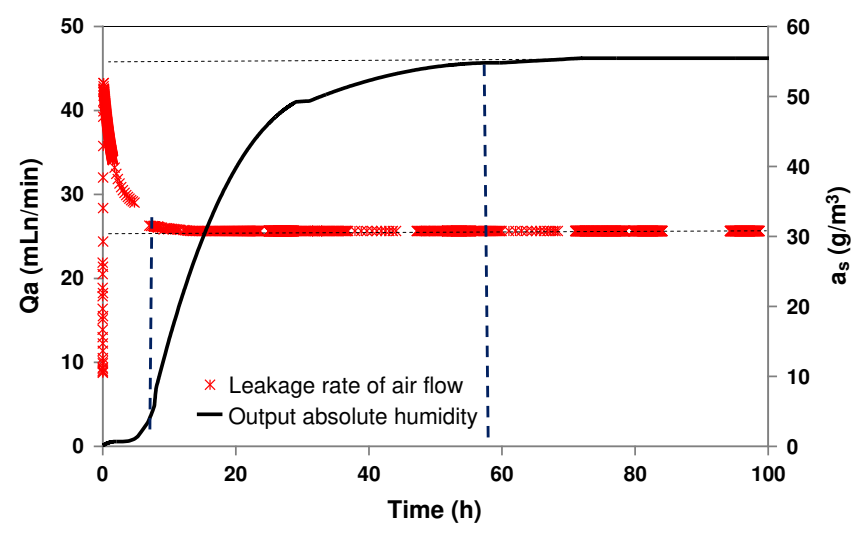

Fig. 8. Evolution of the leakage rate of dry air and the output absolute humidity.

injected mix confirmed this phenomenon [40]. It can however reduce with increasing total pressure of the injected mix.

\subsubsection{Measurement of the steam effect on air permeability}

The effect of the capillary condensation on the air permeability when water vapor percolated through the concrete specimen is highlighted by the following tests. Firstly, the air permeability is measured on a dry specimen. Secondly, an air and steam mix is injected through the same specimen. The experimental conditions are given in Table 5. After reaching stabilization state, the specimen is kept under ambient temperature and its air permeability is measured.

The apparent permeability of both tests for several average pressures is shown in Fig. 9. The permeability and the Klinkenberg coefficient are given in Table 6. After water vapor injection, the air permeability of concrete decreases. To explain this difference of behavior, an assumption is proposed: water condensation in the porous network leads to a decrease in paths available to the gas flow. However, this difference is quite low and close to the reproducibility.

\subsection{Influence of the mechanical loading on the air-steam flow}

The objective of this study is to determine the effect of mechanical loading on air and water vapor leakage rate. Several tests were performed on dry concrete specimens under different levels of compressive loading.

The experimental conditions are close to the LOCA conditions and are equal to $140{ }^{\circ} \mathrm{C}$ for the temperature and 5 bars for the total pressure of the injected fluid. The external surface is kept under atmospheric pressure and at $140{ }^{\circ} \mathrm{C}$. The test conditions are given in Table 7 .

Figs. 10 and 11 show the evolution of the leakage rate of the dry air and the output absolute humidity as a function of the applied stress level.

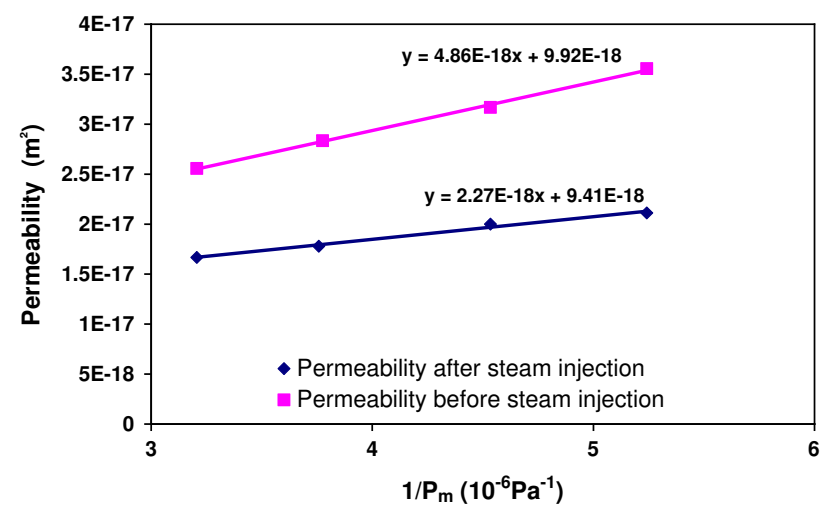

Fig. 9. Measurement of apparent permeability ka before and after steam injection at $120^{\circ} \mathrm{C}$. 
Table 6

Permeability values for different water contents.

\begin{tabular}{lll}
\hline & $\mathrm{k}_{\mathrm{v}}\left(10^{-18} \mathrm{~m}^{2}\right)$ & $\beta(\mathrm{MPa})$ \\
\hline Dry material & 9.92 & 0.49 \\
Material with previously water vapor injection & 9.41 & 0.25 \\
\hline
\end{tabular}

Similar evolution (two stages) is observed for the partially saturated specimens (Fig. 7). So, mechanisms driving it are probably quite similar. Below $80 \%$ of the peak load, nitrogen leakage rate decreases slightly (Fig. 10) due to the closure of pores. Indeed, under the mechanical loading the material porous network decreases and steam condenses faster following the relations of Kelvin-Laplace. It is partially confirmed by the slight decrease in the output absolute humidity below $80 \%$ of the peak load (Fig. 11). Beyond the nitrogen leakage rate (Fig. 10), the output absolute humidity (Fig. 11) increases rapidly due to the gradual material damage. Indeed, the effective pore network available for the fluid transfer grows thanks to the development of cracks for making it easier for the steam mix to flow.

To check this assumption, the value of the molar ratio $r$ (Eq. (8)) of the injected and outgoing fluid is determined for the specimens SP1, SP2 and SP3 (Table 7) under a mechanical preloading ("intact specimen") and a loading equal to $90-95 \%$ of the ultimate compressive strength ("damaged specimen"). This molar ratio is calculated from the Eq. (8) based on the partial pressure ratio. This relation assumes that the gases are ideal.

$r=\frac{n_{v p}}{n_{a s}} \approx \frac{P_{v p}}{P_{a s}}$

where $n_{v p}$ and $n_{a s}$ are the molar quantities of steam and air respectively, the water vapor pressure $P_{v p}$ is measured by two transducers located at the output and input of the specimen (Figs. 3 and 4), the partial air pressure $P_{a s}$ of the injected fluid is determined from the initial total pressure and of the outgoing fluid is equal to the atmospheric pressure.

These results are shown in Fig. 12. It appears that the difference between the ratios $r_{\text {input }}$ and $r_{\text {output }}$ decreases for the damaged specimen. This is due to the fact that the water vapor content increases for the outgoing fluid of the damaged specimen (as assumed previously). Similar observations can also be found in the literature $[22,41,42]$. For the intact specimen, a different behavior is observed: the main gas detected in the outgoing fluid is nitrogen (see Fig. 12 where $r$ is low). This last result shows that undamaged concrete is a good barrier to steam flow. The difference between relative humidity values (both for intact and damaged specimen) can be explained by the appearance of microcracks, which causes a slight decrease of the injected water vapor pressure (and therefore the molar ratio).

\section{Conclusions}

To understand the complexity of steam transfer through concrete, a new device was developed at GeM and described in this article. This first experimental study allowed determining the effect of hydromechanical loading and the steam injection on concrete permeability. Moreover, the substantial influence of the mechanical loading on steam

Table 7

Test conditions.

\begin{tabular}{lllll}
\hline Specimens & $\begin{array}{l}\text { Relative } \\
\text { humidity (\%) }\end{array}$ & $\begin{array}{l}\text { Water vapor } \\
\text { pressure (bars) }\end{array}$ & $\begin{array}{l}\text { Nitrogen } \\
\text { pressure bars) }\end{array}$ & $\begin{array}{l}\text { Total pressure } \\
\text { (bars) }\end{array}$ \\
\hline SP1 & 18.00 & 0.70 & 4.30 & 5 \\
SP2 & 33.46 & 1.37 & 3.64 & 5 \\
SP3 & 49.50 & 1.87 & 3.13 & 5 \\
Output: Pressure $=1$ bar & & & \\
\hline
\end{tabular}

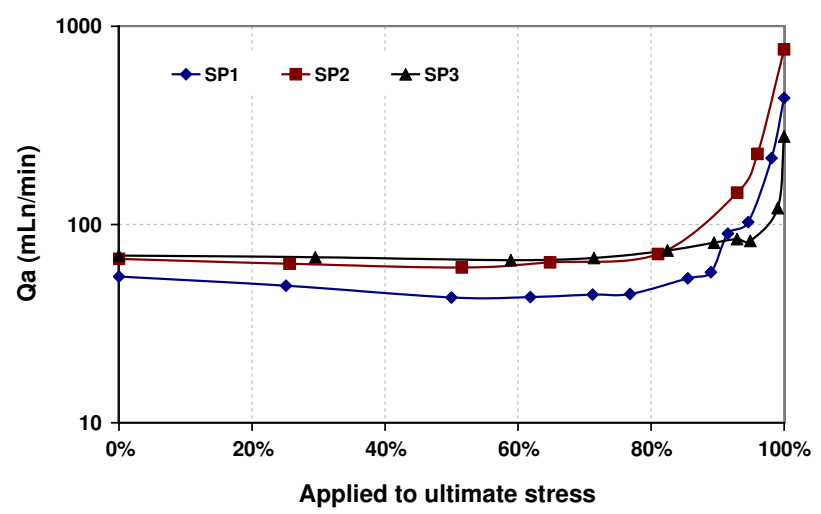

Fig. 10. Evolution of the leakage rate of dry air as a function of mechanical loading.

flow (output absolute humidity and air leakage rate) at LOCA conditions was also underlined.

The main conclusions of the study are emphasized below:

(i) When the compressive loading is lower than $80 \%$ of the ultimate strength, the intrinsic permeability decreases. Beyond this threshold value it increases rapidly. This behavior is amplified with the degree of saturation. However, it is difficult to explain the role of water content on the apparent permeability increase beyond $80 \%$ of the ultimate strength, as permeability is also linked to mechanical damage.

(ii) For both fluids (air and steam), stabilization state is reached after several days. This duration depends on the injection pressure, the pore network available to fluid flow and the process of water condensation.

(iii) Two phases characterize the evolution of the leakage rate of dry air and the output absolute humidity when a concrete specimen is loaded under LOCA conditions. These parameters stay constant during the first phase (below $80 \%$ of the ultimate strength). This is due to the fact that a large number of pores are filled with water that limits the nitrogen and the steam flow. When the concrete specimen is damaged, during the second phase, the leakage rate of both gas and output absolute humidity significantly increases.

These first experimental results underline the effect of steam flow on concrete properties under extreme conditions and the complexity of the steam transfer process. Future experimental works will be focused on the influence of crack width, temperature gradients and the type of loading on the gas/steam permeability.

\section{Acknowledgments}

This study has been performed in the Project ECOBA which is supported by the French National Research Agency (ANR - Agence

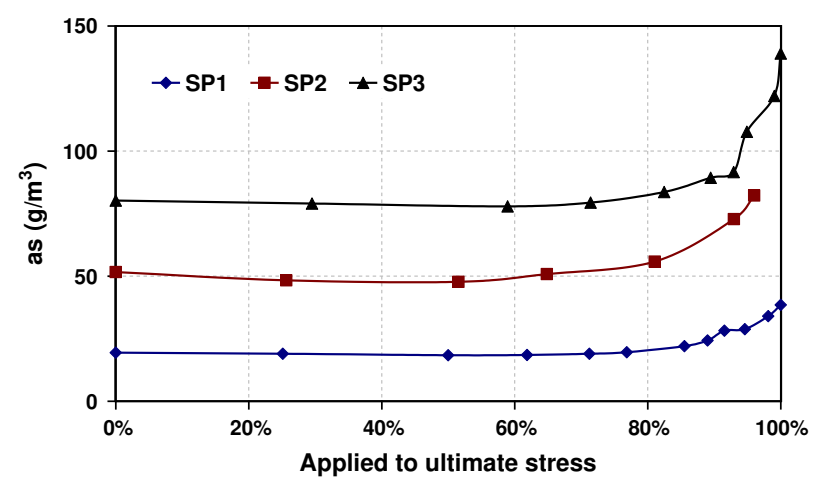

Fig. 11. Evolution of the output absolute humidity as a function of mechanical loading. 


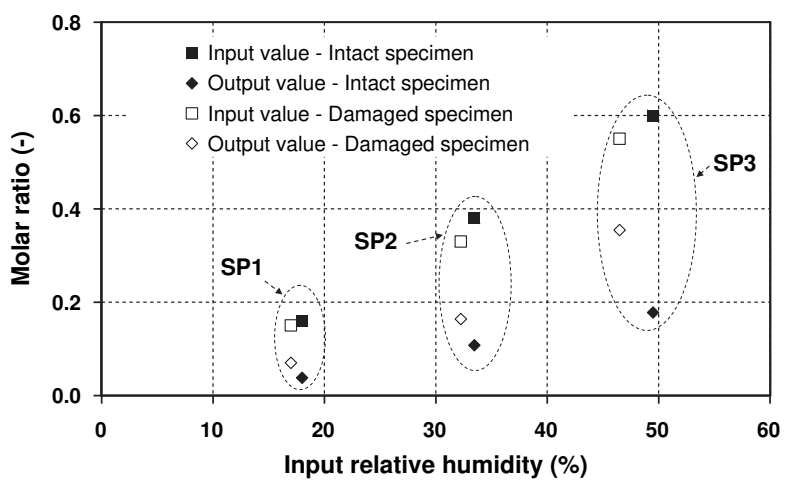

Fig. 12. Influence of cracks on the molar ratio for SP1, SP2 and SP3.

Nationale de la Recherche) under grant number ANR-09-BLAN-0406. The assistance of the Project partners is gratefully acknowledged.

\section{References}

[1] ACI 201, 2R-01, Guide to Durable Concrete, ACI Manual of Concrete Practice, American Concrete Institute, 2008. www.awi-int.org.

[2] L. Mejlbro, E. Poulsen, Diffusion of chlorides in concrete, Mod. Concr. Technol. 14 (2006).

[3] V. Baroghel-Bouny, Conception des bétons pour une durée de vie donnée des ouvrages-Maîtrise de la durabilité vis-à-vis de la corrosion des armatures et de l'alcali réaction - Etat de l'art et guide pour la mise en œuvre d'une approche performantielle et prédictive sur la base d'indicateurs de durabilité, Documen scientifique et technique de l'association Française de Génie Civile, AFGC, Bagneux, Juillet 2004. 252.

[4] V. Baroghel-Bouny, Nouvelle approche performantielle et prédictive fondée sur les indicateurs de durabilité, Club Régional ouvrages d'Art, les sables d'Olonne, France, 08 déc. 2005. 4.

[5] J.W. Figg, Methods of measuring the air and water permeability of concrete, Mag. Concr. Res. 25 (1973) 213-219.

[6] E. Dana, Contribution à la caractérisation des écoulements biphasiques dans les matériaux poreux, Etude expérimentale sur trois grès. Thèse de Doctorat (PhD Thesis in French) Université de Lille I, 1999.

[7] F. Skoczylas, J.P. Henry, A study of the intrinsic permeability of granite to gas, Int. J. Rock Mech. Min. Sci. Geomech. Abstr. 32 (1995) 171-179.

[8] H. Loosveldt, Z. Lafhaj, F. Skoczylas, Experimental study of gas and liquid permeability of a mortar, Cem. Concr. Res. 32 (2002) 1357-1363.

[9] D. Perraton, La perméabilité aux gaz des bétons hydrauliques. Thèse de doctorat (PhD Thesis in French) INSA, Toulouse, 1992.

[10] L.J. Klinkenberg, The permeability of porous media to liquids and gases, American Petroleum Institute, Drilling and Production Practice, 1941. 200-213.

[11] M. Shekarchi, G. Debicki, L. Granger, Y. Billard, Study of leaktightness integrity of containment wall without liner in high performance concrete under accidental conditions - I. Experimentation, Nucl. Eng. Des. 213 (2002) 1-9.

[12] J.-L. Costaz, Confinement - Enceintes, Techniques de l'ingénieur, Réf B 3 290, Génie nucléaire, 1997.

[13] Y. Billard, D. Gérard, L. Coubert, Leakage rate through a non-cracked concrete wall, comparison between two situations: air pressure test and accident conditions, Nucl. Eng. Des. 235 (2005) 2109-2123.

[14] V. Picandet, A. Khelidj, G. Bastian, Effect of axial compressive damage on gas permeability of ordinary and high-performance concrete, Cem. Concr. Res. 31 (2001) 1525-1532.

[15] M. Choinska, A. Khelidj, G. Chatzigeorgiou, G. Pijaudier-Cabot, Effects and interactions of temperature and stress-level related damage on permeability of concrete, Cem. Concr. Res. 37 (2007) 79-88.
[16] T. Sugiyama, T.W. Bremner, T.A. Holm, Effect of stress on gas permeability in concrete, ACI Mater. J. 93 (1996) 443-450.

[17] M. Hoseini, V. Bindiganavile, N. Banthia, The effect of mechanical stress on permeability of concrete: a review, Cem. Concr. Compos. 31 (2009) 213-220.

[18] A. Kermani, Permeability of stressed concrete, Build. Res. Inf. 19 (1991) 360-366.

[19] N. Banthia, A. Biparva, S. Mendess, Permeability of concrete under stress, Cem. Concr. Res. 35 (2005) 1651-1655.

[20] M. Lion, F. Skoczylas, Z. Lafhaj, M. Sersar, Experimental study on a mortar. Temperature effects on porosity and permeability. Residual properties or direct measurements under temperature, Cem. Concr. Res. 35 (2005) 1937-1942.

[21] A. Abbas, M. Carcasses, J.-P. Olivier, Gas permeability of concrete in relation to its degree of saturation, Mater. Struct. 32 (1999) 3-8.

[22] A. Laghcha, Contribution à l'étude des transferts gazeux et liquide au sein des parois en béton endommagées sous sollicitation thermo-hydrique. Thèse de doctorat (PhD Thesis in French) Ecole Doctorale des sciences pour l'ingénieur de Lyon, 2006.

[23] B. Kari, B. Perrin, J.C. Foures, Perméabilité à la vapeur d'eau de matériaux de constructions: calcul numérique, Mater. Struct. 24 (1991) 227-233.

[24] S. Larbi, G. Bacon, S.A. Bories, Diffusion d'air humide avec condensation de vapeur d'eau en milieux poreux, Int. J. Heat Mass Transfer 38 (1995) 2411-2426.

[25] AFPC-AFREM, Méthodes recommandées pour la mesure des grandeurs associées à la durabilité, Compte-rendu des Journées Techniques AFPC-AFREM "Durabilité des Bétons", 11-12 déc. 1997, Toulouse, France, LMDC, 1998.

[26] NFP 18-404, Bétons - Essai d'étude, de convenance et de contrôle - Confection et conservation des corps d'épreuve (French standard), 1981.

[27] M. Carcassès, A. Abbas, J.-P. Olivier, J. Verdier, An optimised preconditioning procedure for gas permeability measurement, Mater. Struct. 35 (2002) 22-27.

[28] G. Villain, V. Baroghel-Bouny, C. Kounkou, C. Hua, Mesure de la perméabilité au gaz en fonction du taux de saturation des bétons, Revue francaise de génie-civil, Transferts dans les bétons et durabilité, 5, 2001, pp. 251-268.

[29] H. Meziani, F. Skoczlas, An experimental study of the mechanical behavior of a mortar and of its permeability under deviatoric loading, Mater. Struct. 32 (1999) 403-409.

[30] D. Chen, Modélisation du comportement hydromécanique d'un mortier sous compression et dessiccation. Thèse de Doctorat (PhD Thesis in French) Université des Sciences et Technologies de Lille, 2005.

[31] S.N. Shoukry, G.W. William, B. Downie, M.Y. Riad, Effect of moisture and temperature on the mechanical properties of concrete, Constr. Build. Mater. 25 (2011) 688-696.

[32] J.-F. Daian, Condensation and isothermal water transfer in cement mortar: Part II transient condensation of water vapor, Transp. Porous Media 4 (1989) 1-16.

[33] J.-F. Daian, Condensation and isothermal water transfer in cement mortar: part I pore size distribution, equilibrium water condensation and imbibition, Transp. Porous Media 3 (1988) 563-589.

[34] F.A.L. Dullien, Porous Media: Fluid Transport and Pore Structure, Academic Press, New York, 1979.

[35] J.R. Philip, D.A. De Vries, Moisture movement in porous materials under temperature gradients, Trans. Am. Geophys. Union 38 (1957) 222-232.

[36] G.L. England, N. Khoylou, Moisture flow in concrete under steady state non-uniform temperature states: experimental observations and theoretical modeling, Nucl. Eng. Des. 156 (1995) 83-107.

[37] C. Abelé, Transferts d'humidité à travers les parois en béton, Guide Technique du CSTB, 2009.

[38] V. Baroghel-Bouny, Caractérisation des pates de ciment et des bétons - Méthodes, Analyse, Interprétations, Editions LCPC (Laboratoire Central des Ponts et Chaussées), 1994.

[39] B. Le Neindre, Tensions superficielles des composés inorganiques et mélanges, Technique de l'ingénieur, 1993.

[40] C. Aubernon, Influence du chargement mécanique, de la température et du fluide percolant sur la perméabilité des bétons. Thèse de doctorat (PhD Thesis in French) Université de Nantes, 2011.

[41] S. Rouchier, G. Foray, M. Woloszyn, J.-J. Roux, Influence of diffuse damage on the water vapor permeability of fibre-reinforced mortar, Transp. Porous Media 93 (2012) 543-559.

[42] R. Cerny, J. Madera, J. Podebradska, J. Toman, J. Drchalova, T. Klecka, K. Jurek, P. Rovnanikova, The effect of compressive stress on thermal and hygric properties of Portland cement mortar in wide temperature and moisture ranges, Cem. Concr. Res. 30 (2000) 1267-1276. 